\title{
Prevention of Bacterial Biofilm Formation on Soft Contact Lenses Using Natural Compounds
}

\author{
Amira M. El-Ganiny ${ }^{1 *}$, Ghada H. Shaker', Abeer A. Aboelazm² and Heba A. El-Dash
}

\begin{abstract}
Purpose: In eye care field, contact lenses (CL) have a great impact on improving vision, but their use can be limited by ocular infection. CL- associated infections can be reduced by good attention to $\mathrm{CL}$ storage case practice. $\mathrm{CL}$-care solutions should be able to control microbial growth on $\mathrm{CL}$. The aim of the study was to evaluate and compare the efficacy of CL-care solutions (found in Egyptian market) with some natural compounds in removal and inhibition of bacterial biofilm formed on soft CL.

Clinical isolates were recovered from patients having conjunctivitis from Benha University Hospital and identified microbiologically. Quantification of biofilm was done using microtiter plate assay. Three multipurpose CL-care solutions were examined for their ability to remove and inhibit biofilm. Also four natural extracts having antibacterial activity and are safe on eye were tested for their anti-biofilm activity.

Results: The major bacterial isolates from eye infections were Pseudomonas aeruginosa (36\%) and Staphylococcus spp. (37.8\%). Only 33.3\% of isolates showed ability to produce weak to moderate biofilm. The tested multi-purpose $\mathrm{CL}$-care solutions showed moderate ability to remove preformed biofilm. Among the tested natural compounds, Calendula officinalis and Buddleja salviifolia extracts showed an excellent efficacy in inhibition of biofilm and also removal of preformed biofilm.

Conclusion: This study demonstrated that isolates from infected eye and CL-cases showed weak to moderate biofilm formation. Calendula officinalis and Buddleja salviffolia extracts showed excellent effect on inhibition and removal of biofilm, these extracts could be added into CL-care solutions which could markedly reduce eyeinfections during $\mathrm{CL}$-wear.
\end{abstract}

Keywords: Biofilm, Contact lenses, Calendula officinalis, Buddleja salviifolia

\section{Introduction}

The human's eye is protected by many factors that prevent ocular infections. However, in certain circumstances, microorganisms gain access to the eye causing variety of infections. The most common bacteria that can cause eye infections are Staphylococcus aureus, Sterptococcus pneumoniae, Pseudomonas aeruginosa, Hemophilus influenza and Klebsiella species [1].

In the eye care field, contact lenses (CL) have a great impact on improving vision, but their use can be limited

\footnotetext{
* Correspondence: amiraganiny@yahoo.com;

amelganiny@pharmacy.zu.edu.eg

'Microbiology and Immunology Department, Faculty of Pharmacy, Zagazig

University, Zagazig, Egypt

Full list of author information is available at the end of the article
}

by ocular infection. CL-wear is the most important risk factor for microbial infections. Wearers of soft lenses are at higher risk than other types of lenses [2]. Wearing contact lenses is associated with changes in the ocular microbiota, the microbiota of ocular conjunctiva was found to be similar to that of skin under the eye [3]. Gram-negative bacteria are the predominant cause of CL-related microbial keratitis with Pseudomonas spp. being the most commonly isolated organism [4-7], while Staphylococcus spp. and Serratia spp. come next [8, 9]. Infections are more likely if there is poor lens hygiene [10]. Microbial infections associated with use of CL may be considerably reduced by attention to risk factors related to CL storage case practice $[11,12]$. It is essential that CL-care solutions should be able to sufficiently 
decrease the amount of pathogens in order to decrease the risk of CL-related infections [13]. In addition, some infectious ocular diseases are due to bacterial biofilm formation, biofilm is highly resistant to many antimicrobials $[14,15]$. Hence, CL-care solutions should have ability to reduce or prevent biofilm formation on CL.

For a long time many people around the world have used plants for therapy. Recently the number of people using plant extracts for therapy increased and the numbers remain on the rise $[16,17]$. Many natural compounds have been used to kill infectious pathogens, others were used for eye remedies because they are known to be safe on eye $[18,19]$. For example, honey was used for treatment of CL induced corneal ulcer; and it shows high in vitro antibacterial activity against ocular isolates [20]. Moreover, honey exhibits anti-biofilm and anti-inflammatory properties, and thus becomes an interesting ophthalmologic agent [21]. The flowers of Calendula officinalis have a good antimicrobial and antibiofilm activities [22, 23]. And owing to their antiinflammatory and healing properties, $C$. officinalis extracts are applied externally to treat conjunctivitis [24]. Jasminum flowers has antibacterial and antifungal activities due to its essential oil content, also leaf extract of Jasminum was used in treatment in of inflamed eyes [25, 26]. Buddleja salviifolia leaves were used for treatment of eye infections by tribes in South Africa. The extract of Buddleja officinalis leaves was used for partial treatment for surface diseases of eyes, it also exhibited a broad spectrum antibacterial activity $[27,28]$.

The need to prevent, reduce, or eliminate microbial biofilm is becoming an important constraint. Strategies, such as coatings with anti-biofilm and developing antibiofilm therapeutics, are promising avenues to reduce the risk of biofilm-associated ocular infection [29]. In the current study honey, jasmine oil, Calendula Officinalis petal extract and Buddleja salviifolia leaves extract were assessed for their activity on inhibition and removal of bacterial biofilm on microtiter plates and soft contact lenses in comparison to three multi-purpose CL-care solutions found in Egyptian market; Renu, Opti-free and Perfect care solutions.

\section{Results}

\section{Identification of bacterial isolates}

A total 111 isolates were recovered from 184 specimens, 81 isolates from clinical samples and 30 isolates from CL cases. The isolated organisms were identified using standard microbiological tests. Among the 111 isolates, 41 (36.9\%) were Gram positive. including 22 (19.8\%) S. aureus, 10 (9\%) S. epidermidis and 9 (8.1\%) S. saprophyticus. The seventy Gram negative isolates include, 40 (36\%) P. aeruginosa, 9 (8.1\%) K. pneumonia, 7 (6.3\%)
Serratia spp., 6 (5.4\%) Moraxella catarralis, 6 (5.4\%) M. lacunata, and only $2(1.8 \%)$ E. coli (Table 1$)$.

\section{Assessment of biofilm formation by spectrophotometric method}

All isolates were tested for biofilm production. Only 12 isolates $(10.8 \%)$ were moderate biofilm forming, 25 isolates $(22.5 \%)$ were weak biofilm forming and 74 (66.6\%) were non biofilm forming. Twenty two $P$. aeruginosa and eight $S$. aureus isolates were biofilm forming. Only four S. epidermidis, two S. saprophyticus and one K. pneumonia isolates were weak biofilm producers (Table 2).

\section{Effectiveness of disinfectant solutions and natural compounds on inhibition of biofilm}

The MICs for the tested disinfectant solutions and natural compounds were determined by broth microdilution method against all biofilm forming isolates. The $\mathrm{MIC}_{90}$ for both Renu and Opti-free were 0.125 of their original concentration. While $\mathrm{MIC}_{90}$ of Perfect solution was 0.25 of its original concentration. The $\mathrm{MIC}_{90}$ for Honey, Calendula officinalis, Jasmine oil and Buddleja salviifolia extract were $125 \mu \mathrm{L} / \mathrm{mL}, 31.2 \mu \mathrm{L} / \mathrm{mL}$, $15.6 \mu \mathrm{L} / \mathrm{mL} .31 .2 \mu \mathrm{L} / \mathrm{mL}$, respectively.

Sub-MICs ( $1 / 2$ and $1 / 4$ MIC) of disinfectants solutions were tested for biofilm inhibition capacity. In case of $1 / 2$ MIC, Opti-free was able to prevent $72.97 \%$ of tested isolates from biofilm formation. Perfect solution prevents $67.56 \%$ of tested isolates, while Renu was able to prevent only $29.72 \%$ of tested isolates (Fig. 1 ).

Table 1 The distribution of specimens and type of bacterial isolates

\begin{tabular}{lllll}
\hline Specimens/MO & Infected eye & Lens case & \multicolumn{2}{l}{ Total } \\
\cline { 5 - 6 } & No. & No. & No. & $\%$ \\
\hline No of Specimens & 116 & 68 & 184 & 100 \\
Negative Specimens & 49 & 46 & 95 & 51.6 \\
Positive specimens & 67 & 22 & 89 & 48.4 \\
Multi-infection specimens & 14 & 8 & 22 & \\
Uni-infection specimens & 53 & 14 & 67 & \\
S. aureus & 20 & 2 & 22 & 19.8 \\
S. epidermidis & 8 & 2 & 10 & 9 \\
S. saprophyticus & 2 & 7 & 9 & 8.1 \\
P. aeruginosa & 30 & 10 & 40 & 36 \\
Klebsiella spp. & 9 & 0 & 9 & 8.1 \\
Serratia spp. & 0 & 7 & 7 & 6.3 \\
M. lacunata & 6 & 0 & 6 & 5.4 \\
M. catarrhalis & 6 & 0 & 6 & 5.4 \\
E. coli & 0 & 2 & 2 & 1.8 \\
Total isolates & 81 & 30 & 111 & 100 \\
\hline
\end{tabular}


Table 2 Distribution of biofilm forming isolates

\begin{tabular}{llll}
\hline Microorganism & Moderate biofilm & Weak biofilm & Total \\
\hline P. aeruginosa & 10 & 12 & 22 \\
S. aureus & 2 & 6 & 8 \\
S. epidermidis & 0 & 4 & 4 \\
S. saprophyticus & 0 & 2 & 2 \\
Klebsiella spp & 0 & 1 & 1 \\
\hline
\end{tabular}

For natural compounds, $\frac{1}{2}, \frac{1}{4}$, and $\frac{1}{8}$ MIC of Honey were able to inhibit $86.5 \%, 75.7 \%$, and $73 \%$ of tested isolates from biofilm production respectively. Also, $\frac{1}{2}, \frac{1}{4}$, and $\frac{1}{8}$ MIC of Calendula extract were able inhibit 100\%, $100 \%$, and $67.6 \%$ of tested isolates from biofilm production respectively. For Buddleja salviifolia extract, $\frac{1}{2}, \frac{1}{4}$, and $\frac{1}{8}$ MIC were able to inhibit $100 \%, 83.8 \%$, and $83.8 \%$ of tested isolates from biofilm production, respectively. Finally, $\frac{1}{2}, \frac{1}{4}$, and $\frac{1}{8}$ MIC of Jasmine oil were able to inhibit $62.2 \%, 62.2 \%$, and $40.5 \%$ of tested isolates from biofilm formation, respectively (Fig. 1).

\section{Effectiveness of disinfectant solutions and natural compounds on removal of pre-formed biofilm}

Different concentrations $(8,4,2$ fold MIC) of disinfectant solutions were tested for their biofilm removal effect. All CL-care solution showed low effect on removal of preformed biofilm. Eight fold MIC of Opti free solution is considered the best in removal of biofilm as it removed biofilm formed by $43.2 \%$ of isolates. While eight fold MIC of Renu solution was able to remove biofilm formed by $27 \%$ of tested isolates and reduced strength of biofilm from moderate to weak in $21.6 \%$ of isolates. Four fold MIC of both Perfect and Renu solutions were able to remove preformed biofilm by $24.3 \%$ of tested isolates (Fig. 2).
The biofilm formed by tested organisms were also exposed to 8, 4 and 2 fold MIC of Jasmine oil, Calendula officinalis extract, and Buddleja salviifolia extract and to 4 and 2 fold MIC of Honey. For Honey 4 and 2 fold MIC were able to remove biofilm formed by $59.5 \%$ for both concentrations. For Calendula officinalis, 8,4 and 2 fold MIC were able to remove biofilm formed by $62.2 \%, 62.2 \%$ and $54.1 \%$ respectively. Regarding Buddleja salviifolia, 8, 4 and 2 fold MIC were able to remove biofilm formed by $70.3 \%, 70.3 \%$ and $51.4 \%$, respectively. Jasmine oil showed the least effect, 8,4 and 2 MIC were able to remove biofilm formed by $18.9 \%, 13.5 \%$ and $10.8 \%$ of isolates, respectively (Fig. 2).

\section{Effectiveness of Calendula and Buddleja extracts on} inhibition of biofilm formation and removal of preformed biofilm on $\mathrm{CL}$

For both Calendula extract and Buddleja extract, $1 / 2$ and $1 / 4$ MIC were tested on biofilm forming S. aureus and $P$. aeruginosa isolates. For Calendula, $1 / 2 \mathrm{MIC}$ was able to inhibit biofilm formation on CL for the two isolates but $1 / 4$ MIC inhibits $P$. aeruginosa and reduces the ability of S. aureus to form biofilm on CL. While $1 / 2$ MIC and $1 / 4$ MIC of Buddleja were able to inhibit biofilm formation for the two isolates.

For both Calendula and Buddleja extracts, 4 and 8 fold of MIC were tested on biofilm forming $S$. aureus isolate and P. aeruginosa isolates. Four and eight MIC of Calendula were able to remove preformed biofilm on soft CL. Four and eight MIC of Buddleja salviifolia were able to remove preformed biofilm of $S$. aureus but it only weakens the biofilm formed by P. aeruginosa.

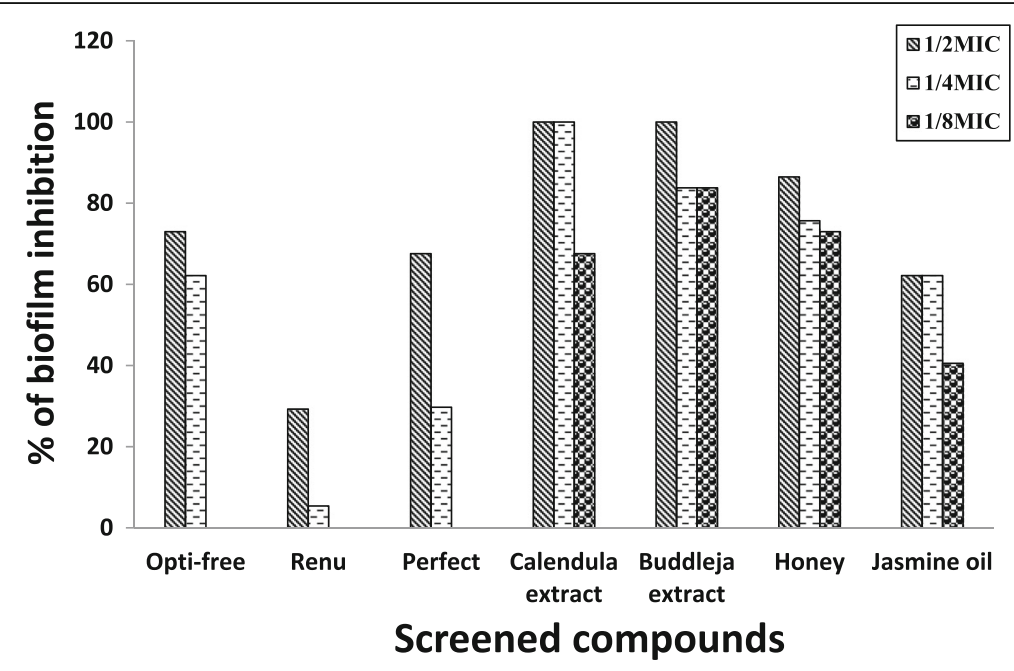

Fig. 1 Percentage of biofilm inhibition by screened CL-care solutions and natural compounds 


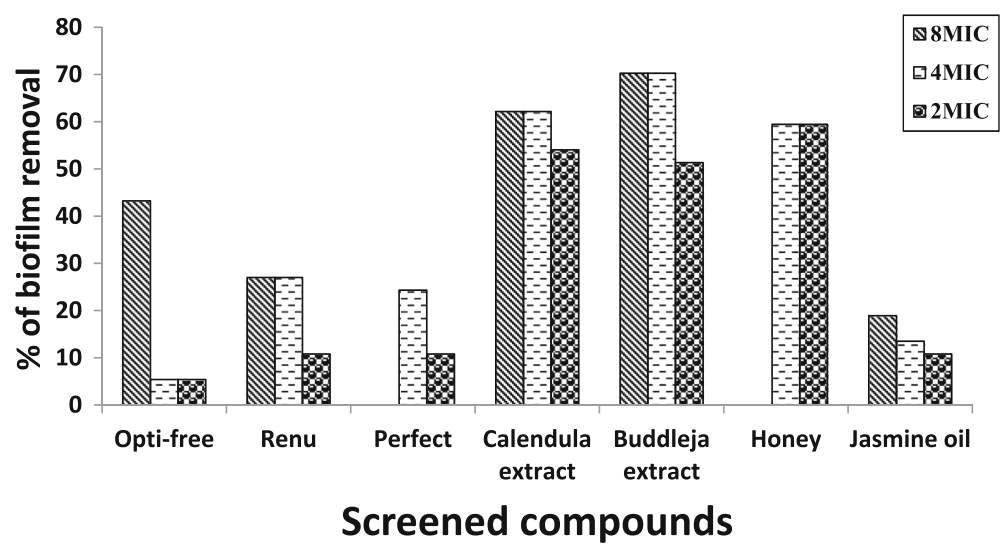

Fig. 2 Percentage of biofilm removal by screened -care solutions and natural compounds

\section{Discussion}

The eye is protected by a number of natural defence mechanisms that reduce the eye infections. However many ocular infections are caused by the use of soft CL [30]. The current study aims to screen for the biofilm forming isolates from infected eyes and CL-cases and to evaluate the anti-biofilm activity of some natural compounds in comparison to three CL-care solutions.

In the present study $P$. aeruginosa was the most isolated organism from eye infection. It was recovered at a frequency of $37 \%$, followed by S. aureus (24.7\%) and Klebsiella spp. (11\%). Previous studies recovered P. aeruginosa at lower frequencies ranging from $1.25-19 \%[1$, 30,31 . The percentage of $S$. aureus was slightly lower than the $32.3 \%$ reported previously [32], but quite similar to previous studies that recovered $S$. aureus at frequency of $22 \%$, and $23.6 \%$ [31, 33].

The major isolates from CL-cases were $P$. aeruginosa, Serratia spp. and S. saprophyticus. P. aeruginosa was isolated in the highest frequency (33.3\%) which agree with the results of previous reports [34, 35]. In current study Serratia was recovered only from CL-cases in a frequency of $23.3 \%$ which is also near to what reported previously [34, 35].

In this study, only $P$. aeruginosa, Staphylococcus spp and klebsiella spp were able to form weak to moderate biofilms. 55\% of isolated $P$. aeruginosa were biofilm producer. A previous study reported lower percentage (33\%) [36], while Oncel and his colleagues found similar result, where $60 \%$ of isolated $P$. aeruginosa formed biofilm [37]. In this study, $36.4 \%$ of isolated S. aureus were biofilm producer, which is lower than the $51.9 \%$ reported previously [30].

The biofilm forming isolates were exposed to sub-MIC concentrations of the three disinfectant solutions found in the Egyptian market to test their ability to inhibit biofilm formation. Our results showed that the three disinfectant solutions have moderate activity against biofilm removal without the rubbing step that is recommended by the manufacturer but some consumers did not comply with lens hygiene procedures [38]. It worth mentioning that the current study is the first to assess anti-biofilm properties of CL-care solutions found in the Egyptian market against bacterial biofilms grown on both polystyrene microtiter plates and soft CL.

Previous study reported that all the tested lens care solutions were effective against planktonic bacterial growth, and were ineffective against bacterial biofilm in vitro [39]. The ability of Renu and Opti-free solutions to remove biofilm formed on silicon hydrogel lenses was assessed previously, the results were unsatisfactory when steps of rubbing and rinsing of lenses were omitted [38].

The tested organisms were also exposed to sub-MIC concentrations of four natural compounds to evaluate their ability to inhibit and remove biofilm. Buddleja salviifolia and Calendula officinalis extracts showed the highest activity in inhibiting biofilm formation followed by honey then jasmine oil. Also Buddleja salviifolia and Calendula officinalis extracts have excellent effect on removal of preformed biofilm, while honey has moderate effect. It was reported previously that honey was able to penetrate biofilm formed $K$. pneumoniae and $P$. aeruginosa [40]. However in our study honey showed moderate activity in removal of biofilm when compared with other tested compounds. Although Jasmine oil showed low MIC $(15.6 \mu \mathrm{L} / \mathrm{mL})$ in our study, but it cannot be considered effective in removal of preformed biofilm.

The phytochemical composition, biological activity and safety of Calendula officinalis extracts are well documented [41-43]. The main active constituents in Calendula are terpenoids, flavonoids, coumarines, quinones and volatile oils [42]. It was previously reported that the extracts of Calendula officinalis decreased the adherence of bacteria on glass tubes, inhibited adhesion on polystyrene surface and caused biofilm detachment [24]. Regarding safety issue, acute toxicity studies in rats 
and mice indicate that the extract is relatively nontoxic. Minimal ocular irritation was seen with one formulation containing lipophilic extract of $C$ officinal and no irritation with other extracts [43, 44].

Buddleja officinalis was used by Chinese Medicine and elsewhere to treat eye diseases, with flavonoids as its effective part [27]. Phytochemical analysis of Buddleja extracts identified polyphenols, flavonoids and phenylethanoid as major components [45, 46]. Buddleja showed antimicrobial activity against Bacillus subtilis, $S$. aureus, E. coli and K. pneumoniae supporting the traditional use of the plant in the treatment of eye infections [28]. In vivo studies in animal models showed that eye drops containing Buddleja can be used safely to treat dry eye $[27,47]$.

\section{Conclusions}

In conclusion, the previous studies supported the results of current study that tested natural compounds could be used as prophylactic agent to prevent ocular infections especially those caused by CL-wear. To our knowledge, the current study is the first to assess the anti-biofilm activity of both Buddleja salviifolia and Jasmine oil. Also it is the first description of a model that study the antibiofilm activity of both Calendula officinalis extract and Buddleja salviifolia extract on soft CL. Our study showed that Calendula officinalis and Buddleja salviifolia extracts have excellent effect on inhibition of biofilm formation and removal of preformed biofilm which make them promising agents that can be added to new more effective CL-care solutions.

\section{Material and methods}

\section{Bacterial isolation and identification}

A total number of 184 specimens were collected, 116 samples were obtained from Ophthalmology Department in Benha Educational University Hospital, Benha, Egypt. While 68 specimens were collected from CLcases of lenses users. The study was approved by the Ethical Committee of our university.

All specimens were taken by moistened sterile swab. The swabs were cultured on chocolate agar, blood agar and MacConkey agar, then incubated at $37^{\circ} \mathrm{C}$ for 24 hours. Gram stained films were prepared from the isolated colonies. Standard Microbiological tests were also done to identify each isolate to the species level [48].

\section{Screened compounds}

Three soft CL-care solutions available in Egyptian market were tested: Renu Multi-purpose solution (Bausch and Lomb-IOM, Milan, Italy), Opti-free solution (Alcon Laboratories, Inc. Fort Worth, Texas, USA) and Perfect care protein remover (Orchidia Pharmaceutical Industries, El Obour, Egypt). Four natural compounds were also tested including honey, jasmine oil, leaves extract of Buddleja salviifolia and petal extract of Calendula officinalis. Honey was purchased from Isis Company (Cairo, Egypt), Jasmine oil, Buddleja salviifolia leaves extract and Calendula officinalis flowers extract were prepared by Morgan chemicals company (Cairo, Egypt), upon authors request. Jasmine oil was extracted from Jasminum officinale petals by hydro-distillation [49] The powdered Calendula officinalis flowers were subjected to extraction with ethanol using soxhlet apparatus as described previously [50] The powdered leaves of Buddleja salviifolia were extracted with $20 \%$ aqueous methanol as reported previously [28].

\section{Detection of biofilm forming isolates}

All isolates were screened for their ability to form biofilm by microtiter plate method with some modifications [51]. Overnight cultures of isolates from trypticase soya agar (TSA) plates were inoculated in tryptone soya broth (TSB), and the turbidity was adjusted to 0.5 McFarland. The suspension were further diluted 1:100 to obtain density of $10^{5}-10^{6}$ cells $/ \mathrm{mL}$. Aliquots of $100 \mu \mathrm{L}$ were distributed in 96-well microtiter plate containing $100 \mu \mathrm{L}$ of TSB with $2 \%$ glucose (TSB-glu), negative control wells were included. The plates were incubated for 48 hours at $37{ }^{\circ} \mathrm{C}$. The content of each tube was aspirated and then washed three times with phosphate buffered saline (PBS) to remove any non-adherent bacteria. $200 \mu \mathrm{L}$ of 99\% methanol was added to each well for $15 \mathrm{~min}$ to fix biofilm. The wells were decanted, left to dry, and stained with $200 \mu \mathrm{L}$ of $2 \%$ Hucker Crystal Violet (CV) for another $15 \mathrm{~min}$. Excess stain was rinsed off gently by water. The plates were air dried; the bound dye was solubilized with $200 \mu \mathrm{L}$ of $33 \%$ (v/v) glacial acetic acid. The Optical Density (OD) was measured at $570 \mathrm{~nm}$ using spectrophotometer (UV-1800 Shimadzu, Japan). The test was made in triplicates. Based on the measured ODs, the tested isolates were classified into four categories; non-adherent, weakly adherent, moderately adherent, and strongly adherent [51].

\section{Determination of minimum inhibitory concentration (MIC) of Screened compounds}

The MICs of disinfectants (CL-care solutions and natural compounds) were determined by broth dilution method according to CLSI [52]. Colonies from biofilm forming isolates were touched with a sterile loop and transferred to Muller-Hinton broth (MHB), the turbidity was adjusted to $0.5 \mathrm{McF}$ arland. The suspension was then diluted 1:100 in MHB.

Two fold serial dilutions of each disinfectant agent were prepared using microtiter plates, $100 \mu \mathrm{L}$ of each dilution are placed in adjacent wells. $100 \mu \mathrm{L}$ of prepared inoculum were added to each dilution, control wells 
were included. Plates were incubated at $37{ }^{\circ} \mathrm{C}$ for $18-20$ hours. The MIC was taken as the lowest concentration of disinfectant which inhibits bacterial growth.

\section{Effectiveness of screened compounds on inhibition of biofilm formation}

Overnight cultures of isolates from TSA plates were inoculated in TSB and the turbidity was adjusted to 0.5 McFarland which was further diluted 1:100 to obtain density of $10^{5}-10^{6}$ cells $/ \mathrm{mL}$. Aliquots of $100 \mu \mathrm{L}$ were distributed in 96-well microtiter plate containing $100 \mu \mathrm{L}$ of sub-MIC of tested disinfectants $(1 / 2$ and $1 / 4$ and $1 / 8$ $\mathrm{MIC}$ ) and incubated in stationary conditions for 48 hours at $37^{\circ} \mathrm{C}$. The content of each well was aspirated, washed three times with PBS, fixed with $200 \mu \mathrm{L}$ of $99 \%$ methanol for $15 \mathrm{~min}$. Then, the wells were decanted, air dried, and stained with $200 \mu \mathrm{L}$ of $2 \% \mathrm{CV}$ for $15 \mathrm{~min}$. Excess stain was rinsed off gently by water, the plates were air dried, and the bound dye was solubilized with $200 \mu \mathrm{L}$ of $33 \%$ glacial acetic acid. The OD was measured using spectrophotometer and used to calculate the strength of biofilm [51].

The ability of disinfectant solution to inhibit biofilm formation on soft CL (Clear vision, Korea) was also tested using the same procedure with some modifications [53]. Pieces of soft CL were placed in each well; $200 \mu \mathrm{L}$ of ethanol-acetone (80:20) was used for solubilization of biofilm. The optical density was determined at $630 \mathrm{~nm}$. Each experiment was performed in three replicates.

\section{Effectiveness of screened compounds on removal of preformed biofilm}

Overnight cultures of isolates from TSA plates were inoculated in TSB. The turbidity was adjusted to 0.5 McFarland and then diluted to 1:100. Aliquots of $100 \mu \mathrm{L}$ were distributed in 96-well microtitre plate containing $100 \mu \mathrm{L}$ TSB-glu and incubated for 48 hours at $37^{\circ} \mathrm{C}$. The content of each well was aspirated, washed three times with sterile PBS; $200 \mu \mathrm{L}$ of two fold serial dilutions of the tested compounds (starting from 8, 4 and 2 fold MIC) were added to each well then incubated for $24 \mathrm{hrs}$ at $37{ }^{\circ} \mathrm{C}$. The wells were decanted and washed three times with sterile PBS, fixed with $200 \mu \mathrm{L}$ of $99 \%$ methanol, air dried, and stained for 15 min with $200 \mu \mathrm{L}$ of $2 \%$ Hucker CV. Excess stain was rinsed by water, plates were air dried, dye was solubilized with $200 \mu \mathrm{L}$ of $33 \%$ glacial acetic acid and OD of de-staining solution was measured using spectrophotometer [51].

For CL, The experiment was repeated with the same procedure with addition of pieces of CL in each well, and $200 \mu \mathrm{L}$ of ethanol-acetone (80:20) was used for solubilisation of biofilm. The optical density was determined at $630 \mathrm{~nm}$. Each experiment was performed in three replicates [53].

\section{Abbreviations}

Cl: Contact lens; CV: Crystal Violet; MIC: minimum inhibitory concentration; OD: Optical Density

\section{Authors' contributions \\ AME designed experiments, interpreted data, wrote the manuscript and perform the submission process, GHS designed the study and revised manuscript, AAA analysed data and revised manuscript, HE performed experiments and interpreted data. All authors read and approved the final manuscript.}

\section{Competing interests}

The authors declare that they have no competing interests.

\section{Publisher's Note}

Springer Nature remains neutral with regard to jurisdictional claims in published maps and institutional affiliations.

\section{Author details}

${ }^{1}$ Microbiology and Immunology Department, Faculty of Pharmacy, Zagazig University, Zagazig, Egypt. ${ }^{2}$ Microbiology and Immunology Department, Faculty of Medicine, Benha University, Benha, Egypt.

Received: 22 October 2016 Accepted: 31 March 2017

Published online: 18 April 2017

\section{References}

1. Bharathi MJ, Ramakrishnan R, Shivakumar C et al (2010) Etiology and antibacterial susceptibility pattern of community-acquired bacterial ocular infections in a tertiary eye care hospital in south India. Indian J Ophthalmol 58(6):497-507

2. Fleiszig SM, Evans DJ (2010) Pathogenesis of contact lens-associated microbial keratitis. Optom Vis Sci 87(4):225-232

3. Shin $H$, Price $K$, Albert $L$ et al (2016) Changes in the Eye microbiota associated with contact lens wearing. mBio 7(2):e00198-16

4. Cheng KH, Leung SL, Hoekman HW et al (1999) Incidence of contact-lens associated microbial keratitis and its related morbidity. Lancet 354:181-185

5. Houang E, Lam D, Fan D et al (2001) Microbial keratitis in Hong Kong: relationship to climate, environment and contact lens disinfection. Transact R Soc Trop Med Hyg 95:361-367

6. Lam DS, Houang E, Fan DS et al (2002) Incidence and risk factors from microbial keratitis in Hong Kong: comparison with Europe and North America. Eye (Lond) 16:608-618

7. Dutta J, Tripathi S, Dutta PK (2012) Progress in antimicrobial activities of chitin, chitosan and its oligosaccharides: a systematic study needs for food applications. Food Sci Technol Int 18(1):3-34

8. Alexadrakis G, Alfonso EC, Miller D (2000) Shifting trends in bacterial keratitis in South Florida and emerging resistance to fluoroquinolones. Ophthalmology 107:1497-1502

9. Willcox MD, Zhu H, Vijay AK (2012) Effect of a warming device on contact lens case contamination. Eye Contact Lens 38(6):394-399

10. Morgan PB, Efron N, Hill EA et al (2005) Incidence of keratitis of varying severity among contact lens wearers. Br J Ophthalmol 89:430-436

11. Dart JK, Stapleton F, Minassian D (1991) Contact lenses and other risk factors in microbial keratitis. Lancet 338(8768):650-3

12. Radford CF, Bacon AS, Dart JK (1995) Risk factors for acanthamoeba keratitis in contact lens users: a case-control study. BMJ 310(6994):1567-1570

13. Hildebrandt C, Wagner D, Kohlmann T (2012) In-vitro analysis of the microbicidal activity of 6 contact lens care solutions. BMC Infect Dis 12:241. doi:10.1186/1471-2334-12-241

14. Fulcher TP, Dart JK, McLaughlin-Borlace $L$ et al (2001) Demonstration of biofilm in infectious crystalline keratopathy using ruthenium red and electron microscopy. Ophthalmology 108(6):1088-92

15. Rossetti S, D'Alessandro L, Pellegrino F et al (2012) The effect of ketorolac on biofilm of Staphylococcus epidermidis isolated from post-cataract endophthalmitis. J Ophthal Inflamm Infect 2:89-93

16. AI-Snafi AE (2015) Therapeutic properties of medicinal plants: review of their antibacterial activity (part I). Int J Pharm Ther 6(3):137-158

17. Rafieian-Kopaei M (2012) Medicinal plants and the human needs. J Herb Med Plarmacol 1(1):1-2 
18. Hammer KA, Carson CF, Riley TV (1999) Antimicrobial activity of essential oils and other plant extracts. J Appl Microbiol 86:985-990

19. Biswas NR, Gupta SK, Das GK et al (2001) Evaluation of Ophthacare eye drops- $A$ herbal formulation in the management of various ophthalmic disorders. Phytother Res 15:618-620

20. Cernak M, Majtanova N, Cernak A et al (2012) Honey prophylaxis reduces the risk of endophthalmitis during perioperative period of eye surgery. Phytother Res 26(4):613-616

21. Majtanova N, Vodrazkova E, Kurilova V et al (2015) Complementary treatment of contact lens-induced corneal ulcer using honey: a case report. Cont Lens Anterior Eye 38(1):61-63

22. Efstratiou E, Hussain Al, Nigam PS et al (2012) Antimicrobial activity of Calendula officinalis petal extracts against fungi, as well as Gram-negative and Gram-positive clinical pathogens. Complement Ther Clin Pract 18(3):173-176

23. Ghaima KK, Rasheed SF, Ahmed EF (2013) Antibiofilm, antibacterial and antioxidant activities of water extract of Calendula officinalis flowers. IJBPR 4(7):465-470

24. Butnariu M, Coradini CZ (2012) Evaluation of biologically active compounds from Calendula officinalis flowers using spectrophotometry. Chem Cent J 6(1):35. doi:10.1186/1752-153X-6-35

25. Rath CC, Devi S, Dash SK et al (2008) Antibacterial potential assessment of Jasmine essential oil against E. coli. Indian J Pharm Sci 70(2):238-241

26. Santhanam J, Abd Ghani FN, Basri DF (2014) Antifungal activity of Jasminum sambac against Malassezia sp. and Non-Malassezia sp. isolated from human skin samples. J Mycol. Article ID 359630, http://dx.doi.org/10.1155/2014/359630

27. Peng QH, Yao XL, Wu QL et al (2008) Effects of extract of buddleja officinalis on prevention of dry eye in castrated rabbits. Zhonghua yan ke za zhi 44(11):1011-1019

28. Pendota SC, Aderogba MA, Ndhlala AR et al (2013) Antimicrobial and acetylcholinesterase inhibitory activities of Buddleja salviifolia (L.) Lam. leaf extracts and isolated compounds. J Ethnopharmacol 148(2):515-520

29. Bispo PJM, Haas W, Gilmore MS (2015) Biofilms in Infections of the Eye. Pathogens 4(1):111-136

30. Hou W, Sun X, Wang Z et al (2012) Biofilm-Forming capacity of Staphylococcus epidermidis, Staphylococcus aureus, and Pseudomonas aeruginosa from Ocular Infections. Invest Ophthalmol Vis Sci 53:5624-5631

31. Rahman ZA, Harun A, Hasan $\mathrm{H}$ et al (2013) Ocular surface infections in north eastern state of malaysia: a 10-year review of bacterial isolates and antimicrobial susceptibility. Eye Contact Lens 39(5):355-60

32. Sherif $\mathrm{ZH}$, Labib FM, Mahmoud AH et al (1976) Acute conjunctivitis in a rural Egyptian community. Bull Ophthalmol Soc Egypt 69(73):1-8

33. Anagaw B, Biadglegne F, Belyhun $Y$ et al (2011) Bacteriology of ocular infections and antibiotic susceptibility pattern in Gondar University Hospital, North West Ethiopia. Ethiop Med J 49(2):117-123

34. Larkin DF, Kilvington S, Easty DL (1990) Contamination of contact lens storage cases by Acanthamoeba and bacteria. Br J Ophthalmol 74(3):133-135

35. Gray TB, Cursons RTM, Sherwan JF et al (1995) Acanthamoeba, bacterial, and fungal contamination of contact lens storage cases. Br J Ophthalmol 79:601-605

36. Coban AY, Ciftci A, Onuk EE et al (2009) Investigation of biofilm formation and relationship with genotype and antibiotic susceptibility of Pseudomonas aeruginosa strains isolated from patients with cystic fibrosis. Mikrobiyol Bul 43(4):563-573

37. Oncel S, Pinar E, Sener $G$ et al (2010) Evaluation of bacterial biofilms in chronic rhinosinusitis. J Otolaryngol Head Neck Surg 39(1):52-55

38. Kilvington S, Lonnen J (2009) A comparison of regimen methods for the removal and inactivation of bacteria, fungi and Acanthamoeba from two types of silicon hydrogel lenses. Cont Lens Anterior Eye 32:73-77

39. Szczotka-Flynn LB, Imamura Y, Chandra J et al (2009) Increased resistance of contact lens related bacterial biofilms to antimicrobial activity of soft contact lens care solutions. Cornea 28(8):918-926

40. Merckoll P, Jonassen T, Vad ME et al (2009) Bacteria, biofilm and honey: a study of the effects of honey on 'planktonic' and biofilm-embedded chronic wound bacteria. Scand J Infect Dis 41(5):341-347

41. Khalid KA, da Silva JAT (2012) Biology of Calendula officinalis Linn: focus on pharmacology, biological activities and agronomic practices. Med Aromat Plant Sci and Biotechnol 6(1):12-27

42. Muley BP, Khadabadi SS, Banarase NB (2009) Phytochemical constituents and pharmacological activities of Calendula officinalis Linn (Asteraceae): A Review. Trop J Pharm Res 8(5):455-465
43. Cosmetic Ingredient Review Expert Panel (2001) Final report on the safety assessment of Calendula extract and C. officinalis. Int J Toxicol 20(Suppl 2):13-20

44. Andersen FA, Bergfeld WF, Belsito DV et al (2010) Final report of the Cosmetic Ingredient Review Expert Panel amended safety assessment of Calendula officinalis derived cosmetic ingredients. Int J Toxicol 29(Suppl 4): 221S-243S

45. Adedapo AA, Jimoh FO, Koduru S et al (2009) Assessment of the medicinal potentials of the methanol extracts of the leaves and stems of Buddleja saligna. BMC Complement Altern Med 9(1):21

46. Sun M, Luo Z, Liu Y et al (2016) Identification of the major components of Buddleja officinalis extract and their metabolites in rat urine by UHPLC LTQOrbitrap. J Food Sc 81(10):H2587-H2596

47. Quan-long W, Qing-hua P, Xiao-lei Y et al (2009) Effects of eye drops with extract of Buddleja officinalis on histo-morphology of lacrimal gland cells of castrated in rats with dry eyes. J Tradit Chin Med 5:007

48. Collee JG, Miles RS, Watt B (1996) Tests for the identification of bacteria, 14th edn. Churchill livingstone, New York

49. Paibon W, Yimnoi C-A, Tembab N et al (2011) Comparison and evaluation of volatile oils from three different extraction methods for some Thai fragrant flowers. Int J Cosmet Sci 33:150-156

50. Roopashree TS, Dang R, Shobha RH et al (2008) Antibacterial activity of antipsoriatic herbs: Cassia tora, Momordica charantia and Calendula officinalis. Int J of Appl Res Nat Prod 3:20-28

51. Christensen GD, Simpson WA, Younger JJ et al (1985) Adherence of coagulase-negative staphylococci to plastic tissue culture plates: a quantitative model for the adherence of staphylococci to medical devices. J Clin Microbiol 22(6):996-1006

52. CLSI (2014) Performance standards for antimicrobial disk susceptibility. tests Twenty-third informational supplement. CLSI document M100-S23. Clinical and laboratory standards Institute, Wayne

53. Yukinobu O, Shinichiro K, Akiyoshi T (2006) Biofilm formation by Staphylococcus epidermidis on intraocular lens material. Invest Ophthalmol Vis Sci 47:2971-2975

\section{Submit your manuscript to a SpringerOpen ${ }^{\circ}$ journal and benefit from:}

- Convenient online submission

- Rigorous peer review

- Immediate publication on acceptance

- Open access: articles freely available online

- High visibility within the field

- Retaining the copyright to your article

Submit your next manuscript at $>$ springeropen.com 